\title{
Influence of Ionic Additives on the Pyrolysis Behavior of Paper
}

\author{
Karin Stadlmann1, Christian W. Klampfl1, Andreas J. Zemann² \\ ${ }^{1}$ Institute of Analytical Chemistry, Johannes-Kepler-University Linz, Linz, Austria \\ ${ }^{2}$ Institute of Analytical Chemistry and Radiochemistry, Leopold-Franzens-University \\ Innsbruck, Innsbruck, Austria \\ Email:andreas.zemann@uibk.ac.at
}

How to cite this paper: Stadlmann, K., Klampfl, C.W. and Zemann, A.J. (2017) Influence of Ionic Additives on the Pyrolysis Behavior of Paper. American Journal of Analytical Chemistry, 8, 774-791. https://doi.org/10.4236/ajac.2017.812056

Received: September 21, 2017

Accepted: December 24, 2017

Published: December 27, 2017

Copyright $\odot 2017$ by authors and Scientific Research Publishing Inc. This work is licensed under the Creative Commons Attribution International License (CC BY 4.0).

http://creativecommons.org/licenses/by/4.0/ (c) (i) Open Access

\begin{abstract}
In the course of this study the influence of ionic additives (sodium, potassium, lithium, magnesium, and manganese as cations; acetate, lactate, malate, malonate, succinate, and citrate as anions) on the pattern of volatile pyrolysis products of finished paper is investigated. The pyrolysis of paper causes a cascade of reaction products. As expected, the most abundant pyrolysis product is levoglucosan, however, along with other volatile products, such as hydroxyl and carbonyl compounds, furan and pyran derivatives, phenols, and other anhydrosugars, respectively. These compounds can easily be separated and characterized online using analytical pyrolysis in combination with gas chromatography (GC) and mass spectrometry (MS) detection. Both the composition and total amount of volatile pyrolysis products are significantly altered when the paper samples contain metal salt ions and salts of organic acids, respectively. Principal Component Analysis (PCA) was employed for the multivariate analysis of the obtained pyrolysis products. This allows for a qualitative interpretation on how the various ionic additives affect the formation of specific pyrolysis products. When organic acids are added onto the paper, the pyrolysis pattern mainly depends on the protic properties of the organic acids (mono/di/triprotic) and to a lesser extent on the type within a protic class (monoprotic acetate or lactate vs.diprotic malate or malonate or succinate vs. triprotic citrate). The pyrolysis pattern of the paper samples is more markedly influenced by the type of metal ions rather than by the type of organic acid. These effects significantly depend on both the valence and the concentration of the specific metal salt.
\end{abstract}

\section{Keywords}

Pyrolysis of Paper, Principal Component Analysis, Ionic Burning Additives 


\section{Introduction}

The thermal degradation of wood and wood products has long been of interest not only towards the understanding of the underlying mechanisms of the combustion chemistry, but also with respect to the formation of the combustion products. On the contrary, finished paper has only been rarely investigated towards its pyrolysis products. Besides cellulose, finished paper often consists of a significant part of filler (e.g. ground and precipitated calcium carbonate, titanium oxide, kaolin, talcum). Depending on the type of paper, the filler contents can reach up to $40 \%-50 \%(\mathrm{w} / \mathrm{w})$ of the paper substance. Filler is added to the paper for various purposes, such as reducing costs, increasing brightness and other optical properties, improvement of sheet formation and dimensional stability of the fiber sheet, and for improving printability.

However, literature on the pyrolysis of finished paper products is rare. Mainly thermogravimetric analysis has been described, reporting the formation of carbon monoxide, carbon dioxide, water, hydrocarbons, and char at different heating rates and atmospheres [1]. Gupta et al. [2] describe the dependence of degradation temperature on heating rate and atmosphere. Baldry et al. [3] report on the formation of carbon monoxide and char when cigarette paper, impregnated with organic and inorganic salts, is pyrolyzed.

On the contrary, reports on the pyrolysis of cellulose are numerous. In an early report, Shafizadeh [4] describes the reaction mechanisms of the cellulose backbone degradation and the formation of levoglucosan as an important product. Arseneau [5] reports specific degradation mechanisms of cellulose using thermogravimetric and differential-thermoanalytical methods. The further degradation of levoglucosan to carbon monoxide, carbon dioxide, and other volatile carbonyl compounds, as well as the existence of acid and base catalyzed reaction paths was investigated by Shafizadeh et al. [6].

Kinetic investigations have been reported by Bradbury et al. [7] and Agrawal [8] [9] assuming a 3-reaction-model where activated cellulose is involved in the further degradation. Diebold [10] published a model involving seven reaction steps. The investigations of Ball et al. [11] considered heating rate, gas flow and water vapour on the reaction cascade forming volatile products. Pouwels et al. [12] identified numerous pyrolysis products using Curie-point pyrolysis and GC/MS.

Essig et al. [13] showed that the presence of $\mathrm{NaCl}$ reduces the amount of levoglucosan produced during hydrolysis while the amount of glycoaldehyde is increasing. They also investigated the presence of other salts, such as sodium carbonate, sodium sulfate, magnesium chloride, and cesium chloride, as well as of oxygen, methanol, and propanol in the pyroylsis atmosphere on the formation of levoglucosan.

The presence of ammonium sulfate and ammonium phosphate, respectively, causes a reduced formation rate of levoglucosan and an increase of water, carbon dioxide, and char, respectively [14]. Dobele et al. [15] report about the influence 
of phosphoric acid and iron (III) ions on the formation of levoglusocsan and levoglucosenone from cellulose. Low concentrations of phosphoric acid below $1 \%$ favour the formation of levoglucosan, whereas higher concentrations of phosphoric acid above $2 \%$ produce more levoglucosenone. The presence of iron (III) ions cause an increased level of levoglucosan compared to untreated cellulose.

In a recent review Dale [16] reports on cellulose pyrolysis kinetics and the existence of intermediate active cellulose. The influence of the chain length of cellulose and of end-group effects during isothermal pyrolysis is subject of a recent paper by Mettler et al. [17]. The conversion of cellulose to furans and small oxygenates is also described by the same group [18]. A comprehensive overview on the pyrolysis of organic molecules is given by Moldoveanu [19].

Generally, the reactions occurring during pyrolysis are complex and greatly depend on external parameters, such as temperature, heating rate, and atmosphere. In addition, structural properties of the cellulosic substrate also play a significant role, such as degree of polymerization, crystallinity, and the presence or absence of salts.

Whereas investigations dealing with the pyrolysis of cellulose containing ionic additives to influence the pyrolysis pathway are published in considerable numbers [15] [20] [21] [22] [23] [24], only little has been reported on the pyrolysis of finished paper containing ionic additives or contaminants [25].

In this paper, the basic focus is primarily laid on receiving a general picture of the effects of anionic and cationic additives on volatile pyrolysis products of paper during online-pyrolysis. For this purpose, principal component analysis (PCA) is applied to interpret the pyrolysis data. By this means, the pyrolysis products can be correlated with respective samples preferably producing more or less of these specific compounds.

\section{Materials and Methods}

\subsection{Chemicals}

All chemicals used in this investigation were of analytical reagent grade. Standard solutions of the salts prepared by dissolving the solid chemicals (purchased from Sigma-Aldrich-Fluka Handels-Ges.m.b.H, Vienna, Austria and Merck $\mathrm{GmbH}$, Vienna, Austria) in ultra-pure water (Barnstead/Thermolyne, Dubuque, IA, USA).

For the series of cationic additives, aqueous solutions of the acetate salts of monovalent $\left(\mathrm{Li}^{+}, \mathrm{Na}^{+}, \mathrm{K}^{+}\right)$and divalent $\left(\mathrm{Mn}^{2+}, \mathrm{Mg}^{2+}\right)$ cations at 3 different concentrations $(150,750$, and $1450 \mathrm{mmol} / \mathrm{L}$, respectively, with reference to the cation) were made and applied to the paper using a laboratory size press.

For the series of anionic additives, aqueous solutions of the free acids (acetic, lactic, malic, malonic, succinic, and citric acids, respectively) were prepared. The sodium and potassium salts, respectively, were then prepared by adding the appropriate amount of a solution of sodium and potassium hydroxide by titration. The monoprotic (acetate, lactate), diprotic (malate, malonate, and succinate) 
and triprotic (citrate) solutions all had a concentration of $725 \mathrm{mmol} / \mathrm{L}$ (based on the anion). In addition, mono sodium and mono potassium salt solutions of malate and citrate were prepared at concentrations of $725 \mathrm{mmol} / \mathrm{L}$, respectively, based on the anion.

\subsection{Paper Samples}

For the impregnation experiments a single grade low substance paper $\left(23 \mathrm{~g} / \mathrm{m}^{2}\right)$ was used. The paper consisted of $72 \%$ alpha cellulose and $28 \%$ precipitated calcium carbonate. Papers with a high amount of filler (calcium carbonate) have specific properties, such as a high opacity and brightness.

The finished paper was then impregnated with solutions containing the ions of interest. The molar on-paper concentrations of the cations $\left(\mathrm{Li}^{+}, \mathrm{Na}^{+}, \mathrm{K}^{+}, \mathrm{Mg}^{2+}\right.$, and $\mathrm{Mn}^{2+}$, respectively) were adjusted to $0.05,0.25$, and $0.50 \mathrm{mmol} / \mathrm{g}$, respectively. The on-paper concentrations of the anions (acetates, lactates, malates, malonates, succinates, and citrates, respectively) were adjusted to $0.25 \mathrm{mmol} / \mathrm{g}$.

The on-paper concentrations of the chemicals were determined using capillary electrophoresis after extraction of the papers with ultra-pure water. For this purpose, $300 \mathrm{mg}$ paper was suspended in $20 \mathrm{~mL}$ water and sonication for 15 minutes. An aliquot was then analyzed using the methods described in chapters 5.1 and 5.2 in reference [26].

After impregnation, paper samples were cut to pieces of uniform size $(5 \mathrm{~mm}$ diameter) using an office puncher.

\subsection{Pyrolysis Gas Chromatography Mass Spectrometry (Py-GC-MS)}

The cut paper samples were pyrolyzed using a Thermo Desorption System (TDS) and an online pyrolysis module PM1 (Gerstel GmbH \& Co. KG, Mülheiman der Ruhr, Germany). Starting at $40^{\circ} \mathrm{C}$ the paper sample is brought to $250^{\circ} \mathrm{C}$ at a heating rate of $60^{\circ} \mathrm{C}$ and kept there for 2 minutes (preset instrument holding time). Pyrolysis was then performed at $500^{\circ} \mathrm{C}$ for 60 s with a heating rate of $20^{\circ} \mathrm{C} / \mathrm{ms}$. After pyrolysis, the system temperature was again kept at $250^{\circ} \mathrm{C}$ for 2 minutes and then cooled down. The flow of Helium was adjusted to $1.4 \mathrm{~mL} / \mathrm{min}$.

The pyrolyzate is then brought to the Cooled Injection System CIS (KAS 4 plus) (Gerstel GmbH \& Co. KG, Mülheiman der Ruhr, Germany) through a heated transfer capillary and focused at a temperature of $-100^{\circ} \mathrm{C}$.

After elevating the CIS temperature to $250^{\circ} \mathrm{C}$ at a rate of $12^{\circ} \mathrm{C} / \mathrm{s}$, the analytes are analyzed by Gas Chromatography using a GC HP 6890 N Series (Agilent Technologies, Palo Alto, CA, USA). The capillary column ZB WAX (Phenomenex, Aschaffenburg, Germany) was $60 \mathrm{~m} \times 0.25 \mathrm{~mm}$ with a polyethylene glycol layer of $0.25 \mu \mathrm{m}$. A temperature gradient for the GC separation was programmed, starting at $40^{\circ} \mathrm{C}$ to $150^{\circ} \mathrm{C}$ (at $5^{\circ} \mathrm{C} / \mathrm{min}$ ) and further for $250^{\circ} \mathrm{C}$ (at $10^{\circ} \mathrm{C} / \mathrm{min}$ ) with a holding time of 20 minutes.

For detection purposes a Mass Spectrometer MS 5973 (Agilent Technologies, 
Palo Alto, CA, USA) with electron impact ionization (EI) at $70 \mathrm{eV}$ was used in full-scan mode $\left(35-400 \mathrm{~m} / \mathrm{z}\right.$ ). The interface was kept at $250^{\circ} \mathrm{C}$ with the ion source at $230^{\circ} \mathrm{C}$.

Triplicate analyses of each paper sample were performed.

\subsection{Data Analysis}

Prior to data analysis, the peak areas of the paper samples were corrected in order to compensate for the steady decrease of peak areas due to the MS intensity decline over the project time. The correction factors for each set of papers were calculated by comparison with the repeatedly measured reference papers.

The data matrix consisting of sample ID (rows) and peak areas of the pyrolysis products (columns) was then analyzed by Principal Component Analysis (PCA) using the software package The Unscrambler X 10.1 64 bit (Camo, Oslo, Norway). Prior to PCA, all peak areas were normalized by their standard deviations in order to compensate for the huge variance in the absolute peak areas of the analytes.

\section{Results and Discussions}

The purpose of this study was to analyze the pyrolysis products of paper samples which have been impregnated with various salt solutions each containing either anionic (mono, di, and triprotic organic acids) or cationic (mono and diprotic inorganic cations) species at various concentrations. The specific goal was to find certain qualitative patterns of the pyrolysis products in dependence of the employed salt solutions.

In the present study the pyrolysis of paper leads to a variety of different reaction products. Table 1 lists the compounds which can be found in a typical pyrogram of paper at $500^{\circ} \mathrm{C}$. The compounds have been divided in various classes (aliphatic carbonyls, cyclic carbonyls, furans, pyrans, cyclic carbonyls, cyclic alcohol, acids, phenols, and anhydro sugars), however, considering that some of the analytes belong to more than one class of compounds. The extent to which certain pyrolysis products are formed not only depends on the respective pyrolysis conditions but also on type and concentration of the employed paper additives.

Figure 1 shows pyrograms (total ion current, TIC) comparing an untreated reference paper along with papers impregnated with solutions of sodium $(\mathrm{Na})$ or magnesium $(\mathrm{Mg})$ acetate, as well as with solutions of various organic acids. When comparing peak intensities some of the peaks increase (e.g. \#7, 8, 13, 14, $44,45)$, some remain at the same intensity level (e.g. \#19), whereas others are reduced in their intensity (e.g. \#12, 42, 46).

For a qualitative analysis of the pyrolysis data multivariate data analysis was used. The primary scope of this investigation was to elucidate how the different cationic and ionic additives cause a predominant or suppressed formation of certain pyrolysis products. 
Table 1. Identified compounds in the pyrolysate of paper*.

\begin{tabular}{|c|c|c|c|c|}
\hline$\#$ & Compound & $\begin{array}{l}\text { Retention } \\
\text { Time [min] }\end{array}$ & $\begin{array}{c}\text { Mass-to-Charge } \\
\text { Ratio }[\mathrm{m} / \mathrm{z}]\end{array}$ & $\begin{array}{l}\text { Compound } \\
\text { Class }\end{array}$ \\
\hline 1 & 2,3-butandione & 6.3 & 43 & aliphaticcarbonyl \\
\hline 2 & crotonaldehyde & 7.6 & 70 & aliphaticcarbonyl \\
\hline 3 & 2 -vinylfuran & 8.1 & 94 & furan \\
\hline 4 & 3 -vinylfuran & 8.8 & 94 & furan \\
\hline 5 & 2-vinyl-5-methyl furan & 9.9 & 108 & furan \\
\hline 6 & 2-methylfuran & 11.7 & 82 & furan \\
\hline 7 & 2-cyclopentenone & 15.5 & 82 & cycliccarbonyl \\
\hline 8 & 2-methyl-2-cyclopentenone & 15.8 & 96 & cycliccarbonyl \\
\hline 9 & 3-furfural & 17.2 & 95 & furan \\
\hline 10 & 2-methoxy propionate & 17.9 & 102 & acid \\
\hline 11 & acetyloxy-2-propanone & 18.0 & 116 & aliphaticcarbonyl \\
\hline 12 & 2 -furfural & 18.2 & 96 & furan \\
\hline 13 & 2-acetyl furan & 19.2 & 95 & furan \\
\hline 14 & 3-methyl-2-cyclopentenone & 19.7 & 96 & cycliccarbonyl \\
\hline 15 & acetoxy-2-butanone & 19.7 & 57 & aliphaticcarbonyl \\
\hline 16 & propionicacid & 19.8 & 74 & acid \\
\hline 17 & 5-methyl-furfural & 20.9 & 110 & furan \\
\hline 18 & protoanemonin & 21.3 & 68 & acid \\
\hline 19 & furfurylalcohol & 22.7 & 98 & furan \\
\hline 20 & 3-methyl-2(5H)-furanone & 24.2 & 98 & furan \\
\hline 21 & 2-hydroxy-2-cyclopentenone & 25.0 & 98 & cycliccarbonyl \\
\hline 22 & 3,5-dimethyl-cyclopentenolon & 25.3 & 126 & cycliccarbonyl \\
\hline 23 & 2-cyclohexenol & 25.7 & 70 & cyclicalcohol \\
\hline 24 & $\begin{array}{l}\text { 2-hydroxy-3-methyl-2- } \\
\text { cyclopentenone }\end{array}$ & 25.9 & 112 & cycliccarbonyl \\
\hline 25 & 2,3-dihydro-5-hydroxy-6-methyl-4H-pyran-4-on & 26.4 & 128 & pyran \\
\hline 26 & 2-hydroxy-3-ethyl-2-cyclopentenone & 26.9 & 126 & cycliccarbonyl \\
\hline 27 & 5-methyl-2(5H)-furanone & 27.1 & 69 & furan \\
\hline 28 & 3-methyl-1,2-cyclopentandione & 27.8 & 112 & cycliccarbonyl \\
\hline 29 & 3-hydroxy-2-methyl-4H-pyran-4-on & 28.0 & 126 & pyran \\
\hline 30 & 4,5-dimethyl-2-formylfuran & 28.2 & 124 & furan \\
\hline 31 & o-cresol & 28.3 & 108 & phenol \\
\hline 32 & phenol & 28.4 & 94 & phenol \\
\hline 33 & p-cresol & 29.3 & 108 & phenol \\
\hline 34 & m-cresol & 29.4 & 108 & phenol \\
\hline 35 & 2-hydroxy- $\gamma$-butyrolactone & 30.5 & 57 & cycliccarbonyl \\
\hline 36 & 3-methyl-2,4-(3H,5H)-furandione & 30.9 & 114 & furan \\
\hline 37 & 3,4-anhydro-D-galactosan & 31.5 & 71 & anhydrosugar \\
\hline 38 & 2,3-anhydro-D-mannosan & 31.5 & 71 & anhydrosugar \\
\hline 39 & 3,5-dihydroxy-2-methyl-4H-pyran-4-on & 31.6 & 142 & pyran \\
\hline 40 & 1,4:3,6-dianhydro- $\alpha$-D-glucopyranose & 32.7 & 69 & anhydrosugar \\
\hline 41 & 5-acetoxy-methylfurfural & 32.9 & 126 & furan \\
\hline 42 & 5-hydroxymethyl-furfural & 33.7 & 97 & furan \\
\hline 43 & hydroxybenzaldehyde & 37.4 & 122 & cycliccarbonyl \\
\hline 44 & 2-methyl-hydroquinone & 41.3 & 124 & cycliccarbonyl \\
\hline 45 & hydroquinone & 42.0 & 110 & cycliccarbonyl \\
\hline 46 & levoglucosan & 54.6 & 162 & $\begin{array}{c}\text { not attributed } \\
\text { (abundant) }\end{array}$ \\
\hline
\end{tabular}

${ }^{\star}$ Online pyrolysis at $500^{\circ} \mathrm{C}$. 


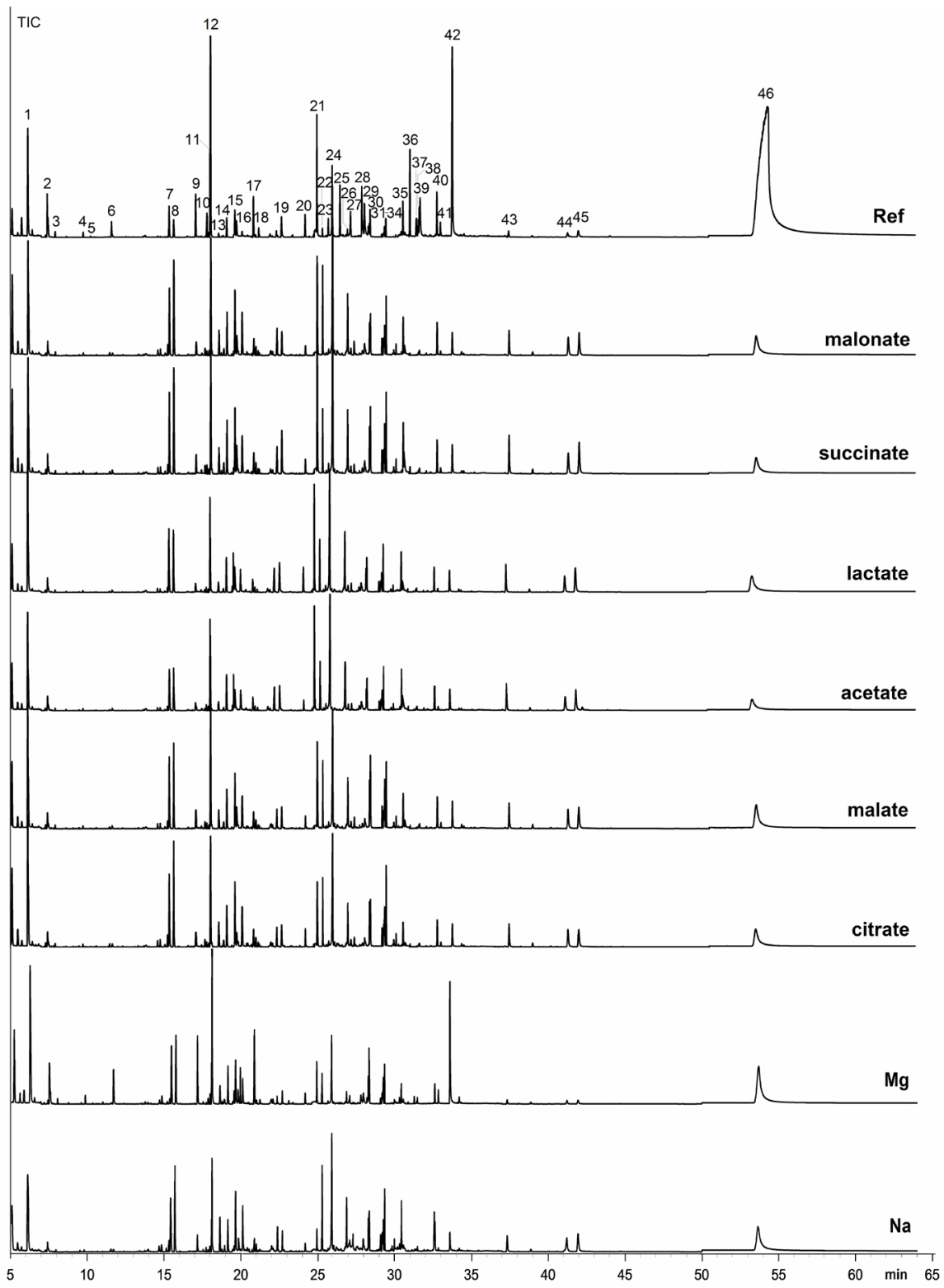

Figure 1. Pyrograms of papers impregnated with water (reference "Ref"), with acetate solutions of sodium ( $\mathrm{Na}$ ) and magnesium $(\mathrm{Mg})$, and the sodium salts of mono, di, and triprotic organic acids. Peak numbers refer to compounds listed in Table 1. Concentrations of impregnation compounds were adjusted to $0.25 \mathrm{mmol} / \mathrm{g}$ paper.

\subsection{Principal Component Analysis (PCA)}

46 different pyrolysis products as listed in Table 1 were investigated in the present study. With the experimental setup (111 pyrolysis experiments) these compounds would form a 46 dimensional data space under the assumption that they were completely independent from each other without any correlation whatsoever. However, the probability that all 46 compounds formed during pyrolysis of the paper samples are completely orthogonal and independent from each other is very low. On the contrary, it is also highly unlikely that the pyrolysis products are affected in exactly the same way during all the experiments, be- 
cause this would mean that the experimental variations would have no effect on the formation of the various pyrolysis products. The reality will be found somewhere in between these extremes. Some paper additives will have a stronger influence the formation of the pyrolysis products and, on the contrary, other additives will have a lesser effect. One way to deal with a situation where several variables correlate while others do not would be a quantitative comparison of the effects among all variables during all experiments. However, this would require a laborious comparison of the data with numerous correlation graphs of all 46 compounds at all experimental conditions (111 experiments).

Principle Component Analysis (PCA) transforms the original data set of possibly correlated variables into a set of uncorrelated latent variables which are called Principal Components (PCs). These PCs basically represent coordinate axes of a newly calculated coordination system with the first PC accounting for as much as possible of the variance of the original data, the second PC for as much as possible of the remaining variability, and so forth. As a consequence, the dimensionality of the data set as generated in this study can be dramatically reduced. Additional information is given by stating the percentage of the explained variance of the original data set for each Principal Component. The higher this percentage, the more of the original information is represented by the analysis results.

The results of a PCA are usually depicted using separate graphs, with the scores plot depicting the samples and the loadings plot showing the variables. A two dimensional loadings plot shows the extent of the correlation of certain variables (pyrolysis products) becomes easily visible. Each data point in the plot represents a pyrolysis product with a higher degree of correlation the closer they are located to each other in the loadings plot; data points close to the origin of the new coordinate system are independent of the experimental conditions.

In the scores plot, the individual data points represent different pyrolysis experiments and also indicate regions of similar properties. Paper samples with their respective additives which cause similar pyrolysis patterns are located closer together than samples which produce different pyrolysis products.

\subsection{Effect of Anionic Additives}

The graphs in Figure 2 show the scores plot (above) and loadings plot (below) of a PCA of the pyrolysis data of the anion impregnation series. More than three quarters $(76 \%)$ of the variance of the original data space (46 variables, 48 samples) are explained by only two dimensions (PC1 59\%, PC2 17\%). This means that many of the pyrolysis products are at least partly correlated and the most important effects can be explained with a high amount of statistical probability using a projection of the data on only two dimensions.

At first sight, the scores plot of the anion series (top of Figure 2) suggests a distinction of the impregnated paper samples into separated areas in the plot regarding certain types of anions as impregnation compounds. Plain reference 


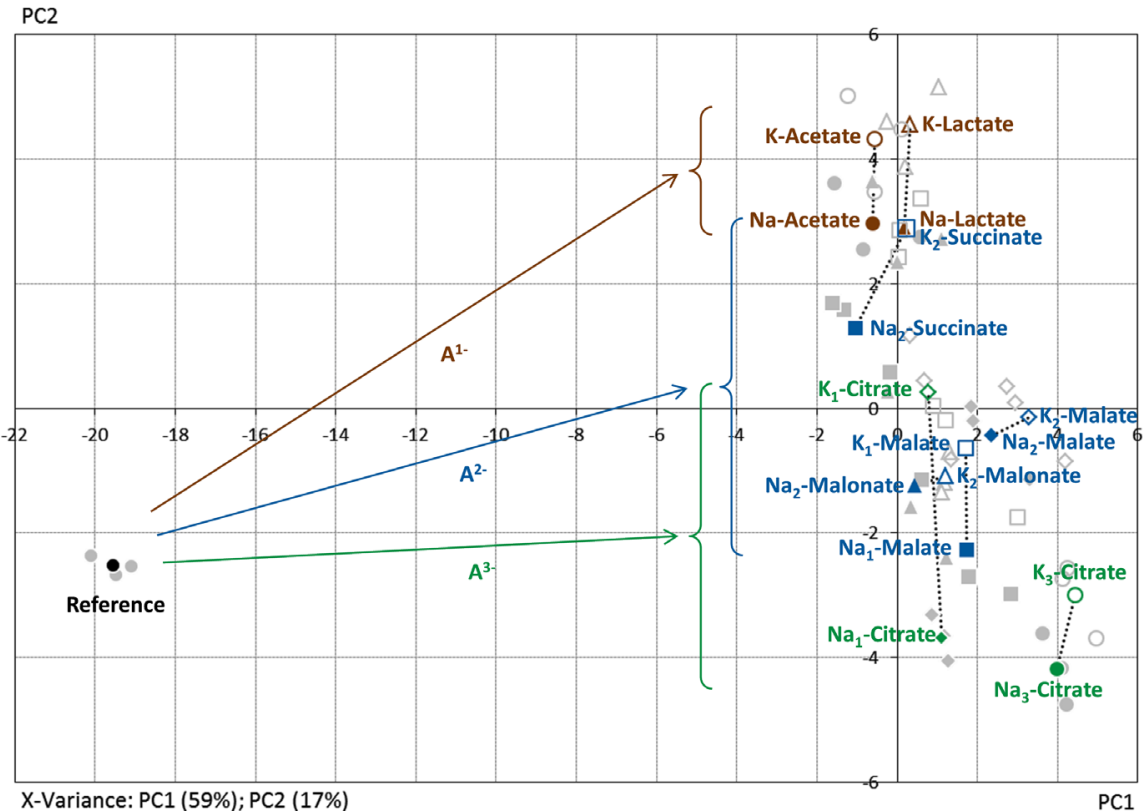

(a)

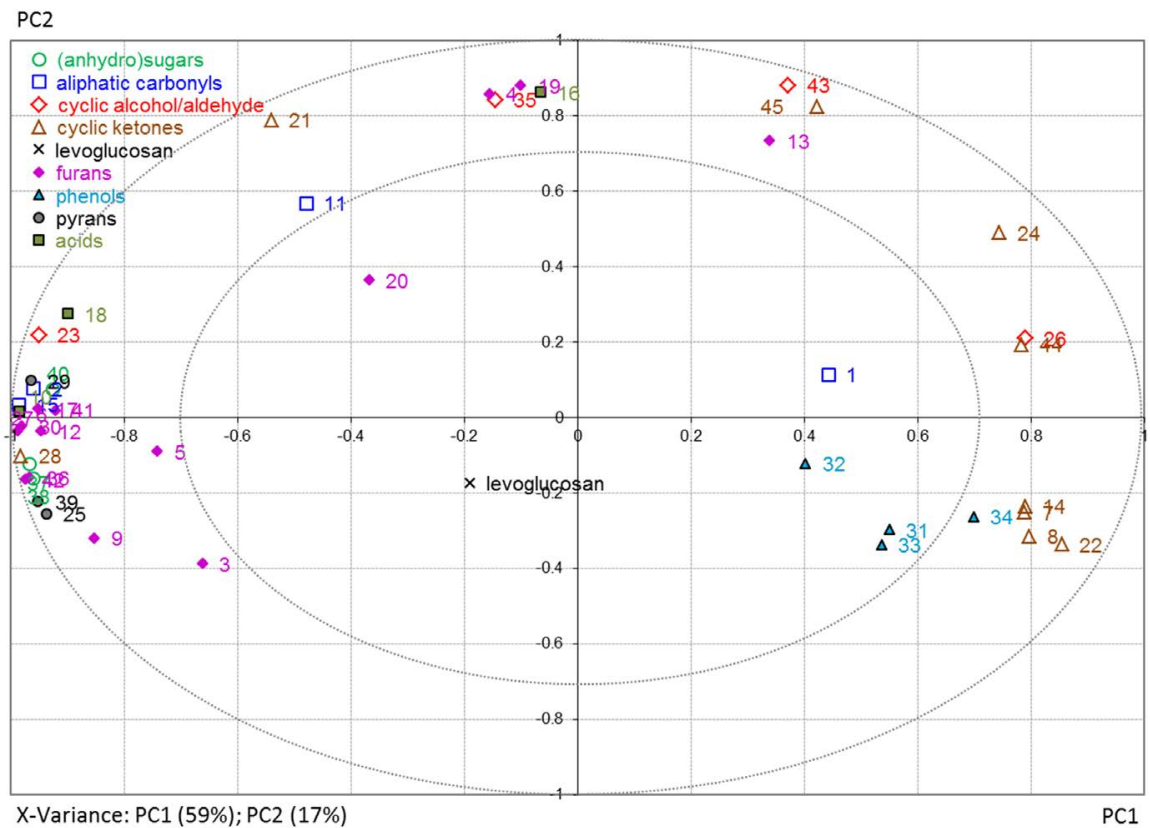

(b)

Figure 2. Scores (above) and Correlation Loadings (below) plots of the pyrolysis data from paper samples impregnated with various anionic salt solutions. Color assignments of Scores and Loadings Plots do not correspond!

paper produces a significantly different pyrolysis pattern compared to paper samples which have been impregnated with ionic additives.

The reference samples are located in the left hand side of the scores plot and separate mainly along the PC 1 axis from the impregnated papers which are located in the middle region of the PC 1 axis close to the origin. This separation of reference papers and impregnated papers, respectively, along the PC 1 axis is 
mainly caused by the different pyrolysis products and accounts for $59 \%$ of the variance of the original data set. The subsequent separation within the paper samples along the PC 2 axis is significantly less marked (17\%) and is obviously due to the variation caused by the different classes of organic acids used for impregnation.

The lower graph in Figure 2 depicts the correlation loadings plot of the PCA and represents the position of the pyrolysis products relative to the respective samples in the scores plot. The two dashed circles in the correlation loadings plot correspond to the "circles of correlation" and help to determine whether the influence of a data point is significant or not. In contrast to the regular loadings plot which works with the actual loadings values, the distances on the axes of the correlation loadings plot are normalized within the range of -1 to +1 . Variables of significant influence are located between the outer and inner circle.

A comparison of scores and loadings plots reveals that paper samples impregnated with monoprotic anions (acetate, lactate) cause a significantly higher formation of specific furans (3-vinylfuran, furfuryl alcohol, 2-acetyl-furan), hydroquinone, hydroxybenzalehyde, propionic acid, and 2-hydroxy- $\gamma$-butyrolactone during pyrolysis compared to papers containing salt of di- and triprotic acid salts. The latter impregnation compounds drive the pyrolysis towards a higher concentration of specific cyclic carbonyls (2-methyl-2-cyclopentenone, 3,5-dimethyl-cyclopentenolon, 3-methyl-2-cyclopentenone, and

2-cyclopentenone), as well as phenolic compounds (phenol and cresols). However, the complexity of the pyrograms generally decreases with impregnated papers. The formation of compounds located in the left part of the loadings plot (acids, anhydrosugars, pyrans and specific furans) is predominant with untreated papers. The concentration of the most abundant pyrolysis product, levoglucosan, is also reduced with impregnated papers.

In addition, other effects become obvious in the scores plot of Figure 2. At first, the pyrograms of papers treated with the sodium salt of the same acid differ slightly from the potassium salts. Potassium salt containing papers are located slightly above the respective sodium salts in Figure 2. This means that during pyrolysis they produce a slightly higher concentration of specific furans (3-vinyl furan, furfurylalcohol, 2-acetyl furan), cyclic carbonyls (2-hydroxy- $\gamma$-butyrolactone, hydroxyl benzaldehyde, hydroquinone), and propionic acid.

At second, the pyrograms of papers with the mono sodium (or mono potassium) salt of citrate and malate, respectively, differ from the pyrograms of the respective fully saturated salts (trisodium and tripotassium citrate, disodium and dipotassium malate, respectively). This can be illustrated in more detail after a PCA calculation leaving out the reference samples. In the scores plot of Figure 3 the impregnated the paper samples separate according to their protic character, with papers containing monoprotic acids (acetate and lactate) at the left hand side of the PC 1 and papers impregnated with a triprotic acid (citrate) at the right hand side. Although the explained variance in this PCA (47\% and $18 \%$, 


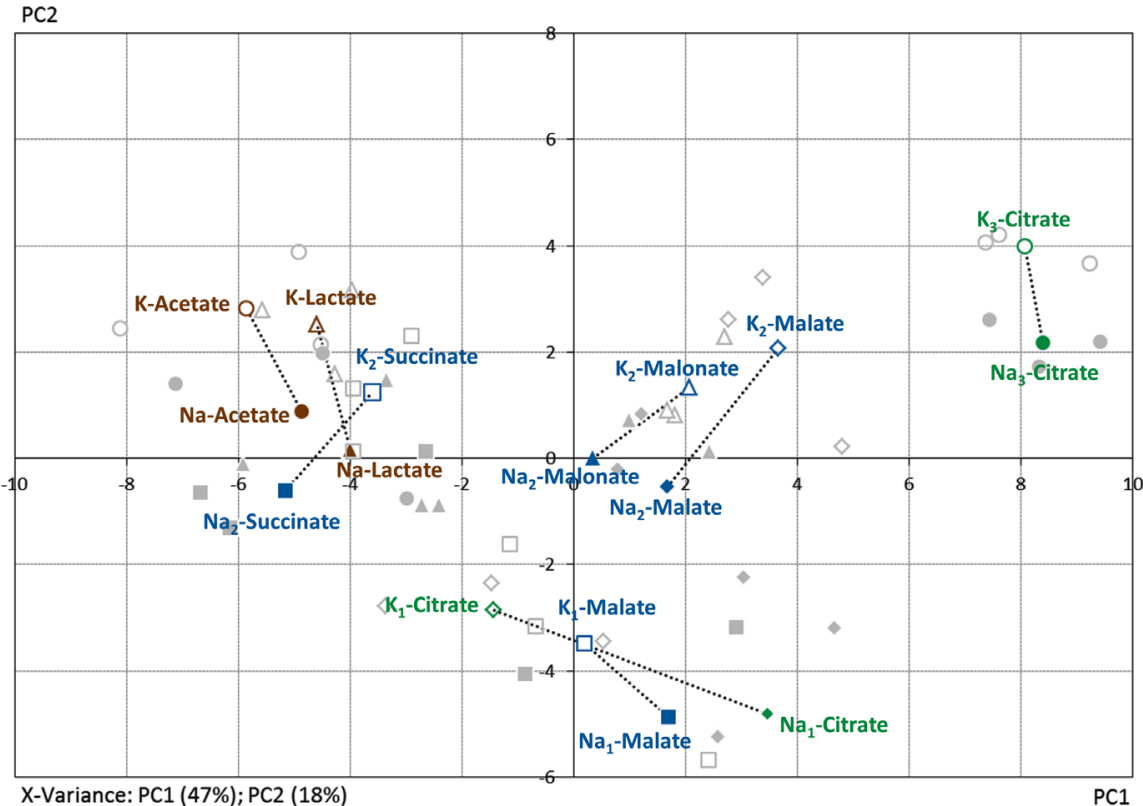

(a)

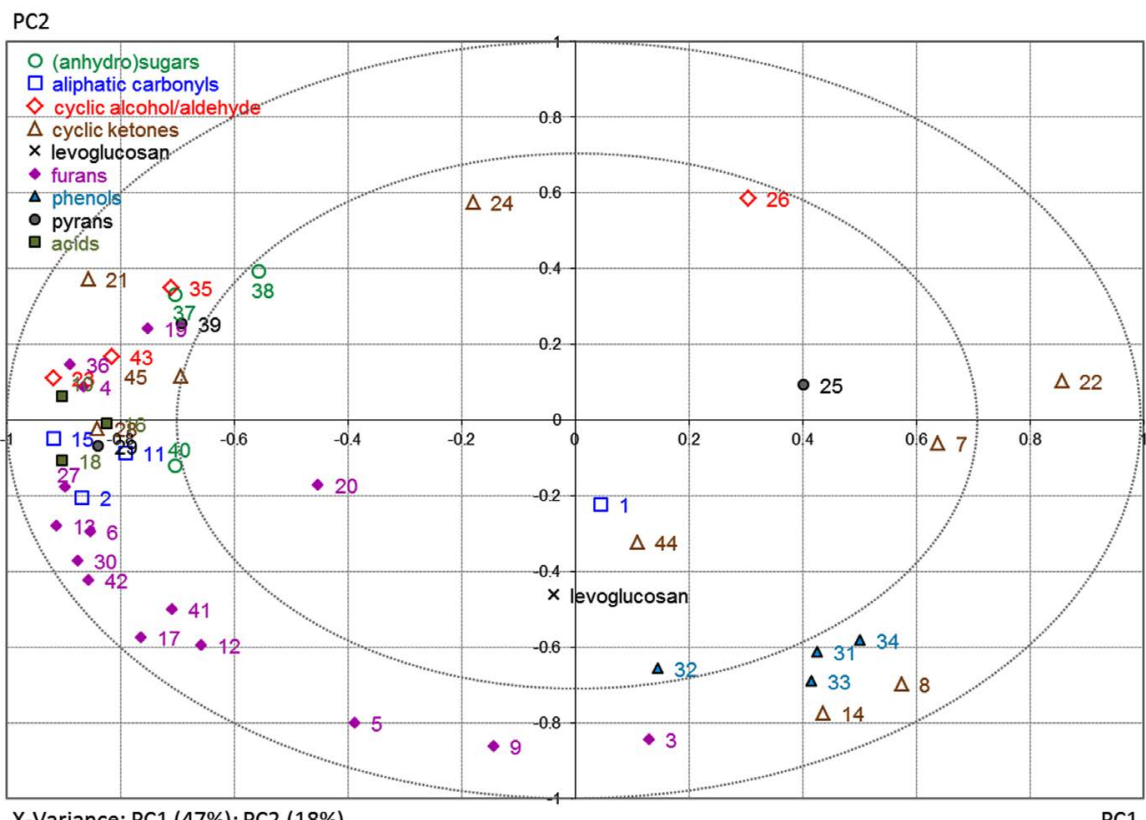

X-Variance: PC1 (47\%); PC2 (18\%)

(b)

Figure 3. Scores (above) and Correlation Loadings (below) Plots of the pyrolysis data from papers samples impregnated with various anionic salt solutions without reference samples. Color assignments of Scores and Loadings Plots do not correspond!

respectively), is lower for the first two PC's compared to Figure 2 it is sufficiently high for the required purpose of explaining the effects. The mono sodium and mono potassium salts of citrate and malate, respectively, can be clearly distinguished from the respective fully saturated salts.

Most of the pyrolysis products are located in the left half (negative PC 1) of the correlation loadings plot in Figure 3. When compared to the scores plot, this 
region generally corresponds to the papers impregnated with single or divalent anions. Separated into the classes of compounds, cyclic alcohols and aldehydes, as well as acids are mainly produced by the acetate and lactate samples (both sodium and potassium), respectively, which are located in the left hand side of the loadings plot. Anhydrosugars (except for levoglucosan) come to lie in the upper left quadrant and correspond to the potassium salts of the monovalent acids. Phenols are clustered in the right lower quadrant which matches the region where the monosodium salts of citrate and malate are found in the scores plot.

Papers impregnated with the salts of higher charged carboyxylic acids (far positive side of PC1) seem to reduce the complexity of the pyrograms leading to a considerably lower variety of volatile pyrolysis products. The concentration of levoglucosan (\#46), however, is not significantly influenced by one or the other impregnation salt as indicated by its position in the loadings plot of Figure 3 (near the PC 2 axis within the inner circle of correlation).

This behavior indicates that the degree to which the acid anions are saturated by metal cations mainly determine the pattern of the pyrolysis products rather than the formal protic character of the acid anions.

It is known from the literature that the presence of alkaline cations significantly affects the mechanisms of thermal degradation of lignocellulosic materials. The cations cause a fragmentation of the cellulosic backbone rather than a depolymerization [27]-[32]. In addition, gas yields increase while liquid yields decrease. Thus it can be assumed that the catalytic effect from additives is due to the involved cations rather than the type of acid anion.

\subsection{Effect of Cationic Additives}

In order to investigate the effect of various types of cations on the pyrolysis pattern in more detail, papers impregnated with solutions of acetates of monovalent $\left(\mathrm{Li}^{+}, \mathrm{Na}^{+}\right.$, and $\left.\mathrm{K}^{+}\right)$and divalent $\left(\mathrm{Mg}^{2+}, \mathrm{Mn}^{2+}\right)$ cations, respectively. Similar to acid anions of different formal valence, the pyrolysis pattern of the paper samples impregnated with different cations also show a distinctive pattern, as depicted in the upper graph of Figure 4.

The scores plot of the PCA generated by the paper samples impregnated with cationic additives show a distinctive separation of both valence as well as of the concentration of the respective cation $(0.05,0.25$, and $0.50 \mathrm{mmol} / \mathrm{g}$ as low, medium, and high concentrations, respectively). Starting from untreated reference papers located in the left upper quadrant of the scores plot, the monovalent cations clearly separate from the divalent cations along the PC 2 with increasing concentration. The divalent cations show a significantly lesser influence on the pyrolysis pattern compared to the monovalent cations, as they are closer to the reference papers. Compared to the paper samples with the anionic additives, a clear dependence on valence is observed with the cationic additives.

The variances explained by the first and second principal components are 59\% and $20 \%$, respectively. This means that the results of a series of 60 experiments 


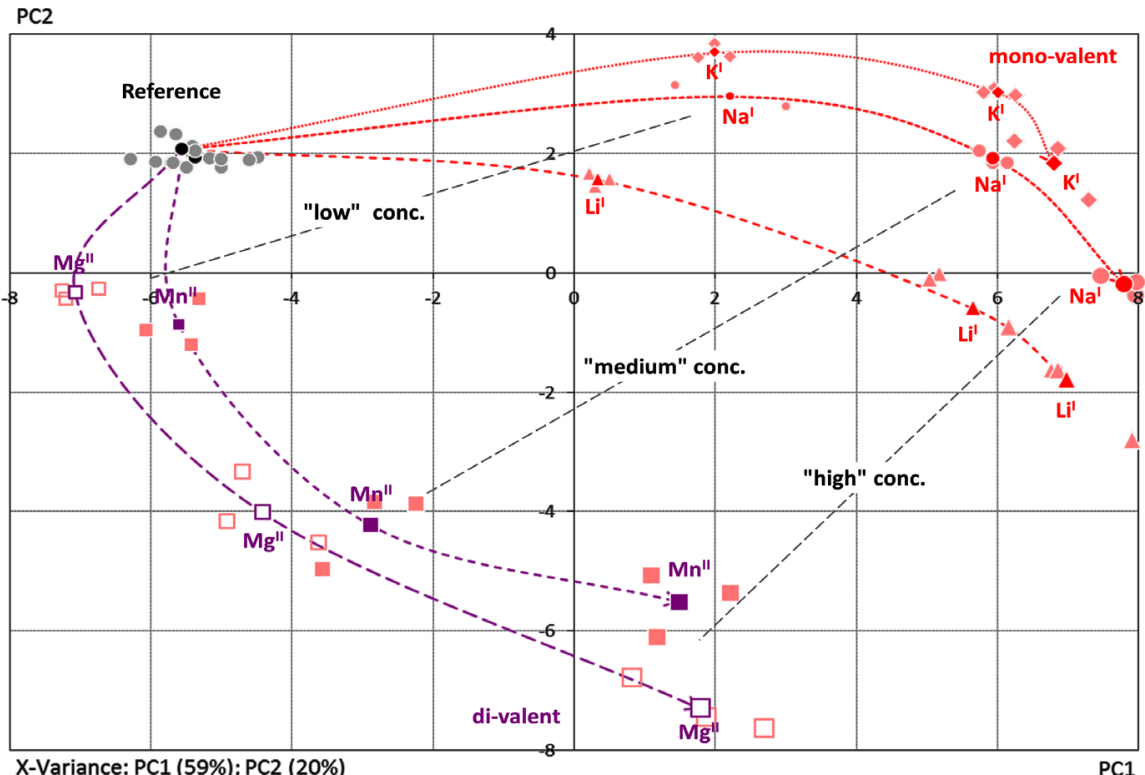

(a)

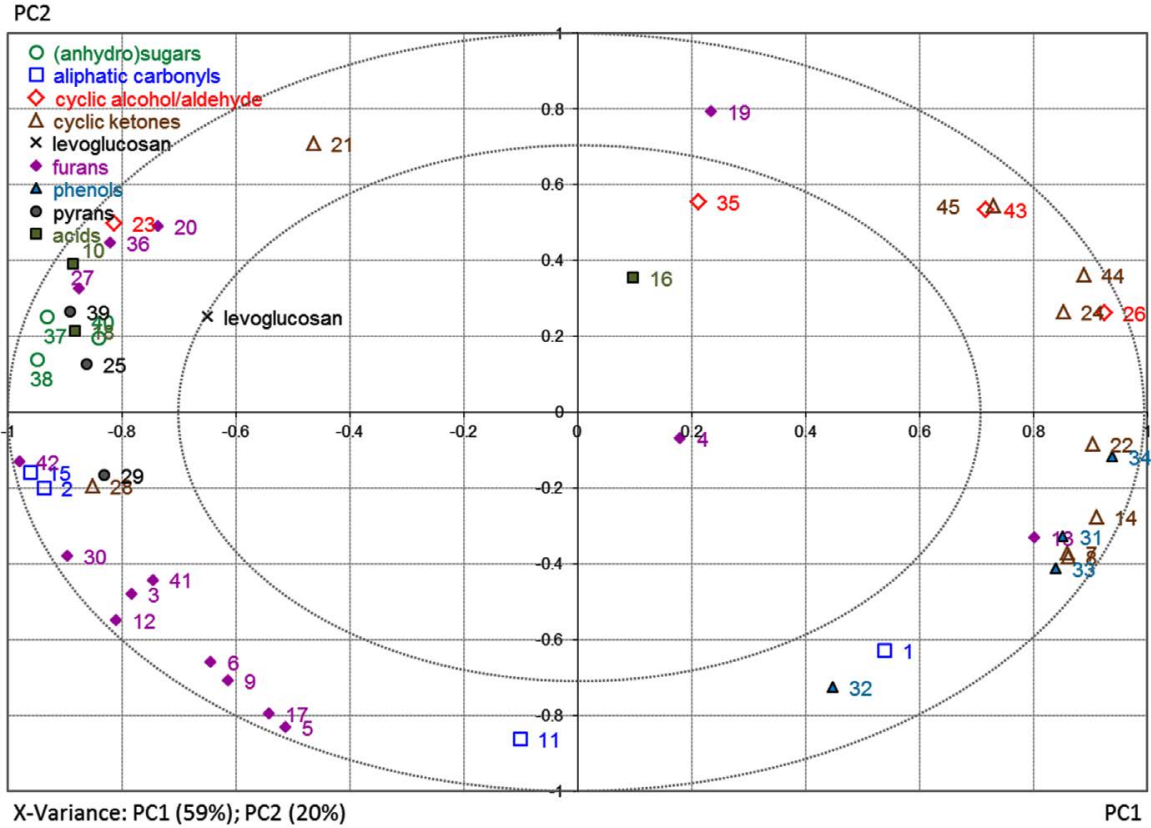

(b)

Figure 4. Scores (above) and Correlation Loadings (below) Plots of the pyrolysis data from paper samples impregnated with various cationic salt solutions. Color assignments of Scores and Loadings Plots do not correspond!

generating 46 pyrolysis products can be reduced to a two dimensional plot still explaining almost $80 \%$ of the total variance of the whole experimental space.

The biggest influence in the cationic scores plot, however, can be attributed to the different concentrations of the cations on the papers rather than to the type of additive. With increasing concentrations, the paper samples clear away from the reference samples moving towards the right hand side of the plot along the PC 1. Obviously, monovalent cations have a much stronger influence on the py- 
rolysis behavior of papers compared to divalent cations. The lowest concentration of the series of monovalent cations is located in the middle of PC 1, at roughly the same position where the highest concentration of the series of the divalent cations ends. This depicts the stronger influence of monovalent cations. In addition, mono and divalent cations separate along the PC 2 axis and can be distinguished by specific pyrolysis products (lower graph in Figure 4).

Pyrans and furans are produced at higher concentrations by paper samples impregnated with low and medium concentrations of the divalent cations (left hand side of the lower left quadrant). Sugars and acids (except for propionic acid) cluster in the outer left positive region of PC 1, corresponding to the reference samples. On the opposite side, high concentrations of monovalent cations cause significantly higher concentrations of phenols and specific cyclic carbonyls (2-hydroxy $\gamma$-butyrolactone, hydroxy benzaldehyde, hydroquinone, 2-ethyl-hydroquinone, 2-hydroxy-3-methyl-2-cyclopentenone, 2-hydroxy-3-ethyl-2-cyclopentenone, 2-hydroxy-3-ethyl-2-cyclopentenone) during pyrolysis. In contrast to the samples impregnated with anionic additives, the concentration of levoglucosan (left upper quadrant in the loadings plot of Figure 4) is reduced by all types and concentration levels of cationic additives.

This is in well accordance with the literature where alkaline and earth alkaline ions in wood induce low levels of levoglucosan [32]. These cations also induce high char and low tar yields.

\subsection{Combined Anionic and Cationic Effects}

In order to distinguish between the effects of anions and cations on the pyrolysis patterns, the pyrolysis products of both series are analyzed together and discussed using one model.

The upper graph of Figure 5 depicts the combined experiments of both anionic and cationic additives. The first two PC's explain $76 \%$ of the total variance of the chromatographic data (PC 1: 63\%; PC 2: 13\%). For the cationic additives the scores plot looks almost identical to the scores plot in Figure 4 (without anionic additives). When compared to the anionic data set in Figure 2, the area with the anionic additives looks almost similar, however, only slightly shifted towards the positive side of the PC 1 axis.

This indicates that the pyrolysis pattern is predominantly determined by the type and concentration of the cationic additives and to a much lesser extent by the anionic additive.

The higher the on-paper concentration of an additive is chosen (especially for the acid anion and the monovalent cations) the lower concentrations of the compounds are produced during pyrolysis. These compounds are located on the left-hand side of the loadings plot in Figure 5 (acids, sugars, pyrans, furans).

\section{Conclusions}

The results of the pyrolysis of a series of papers impregnated with certain concentrations of mono, di, and triprotic anions and of mono and divalent cations 


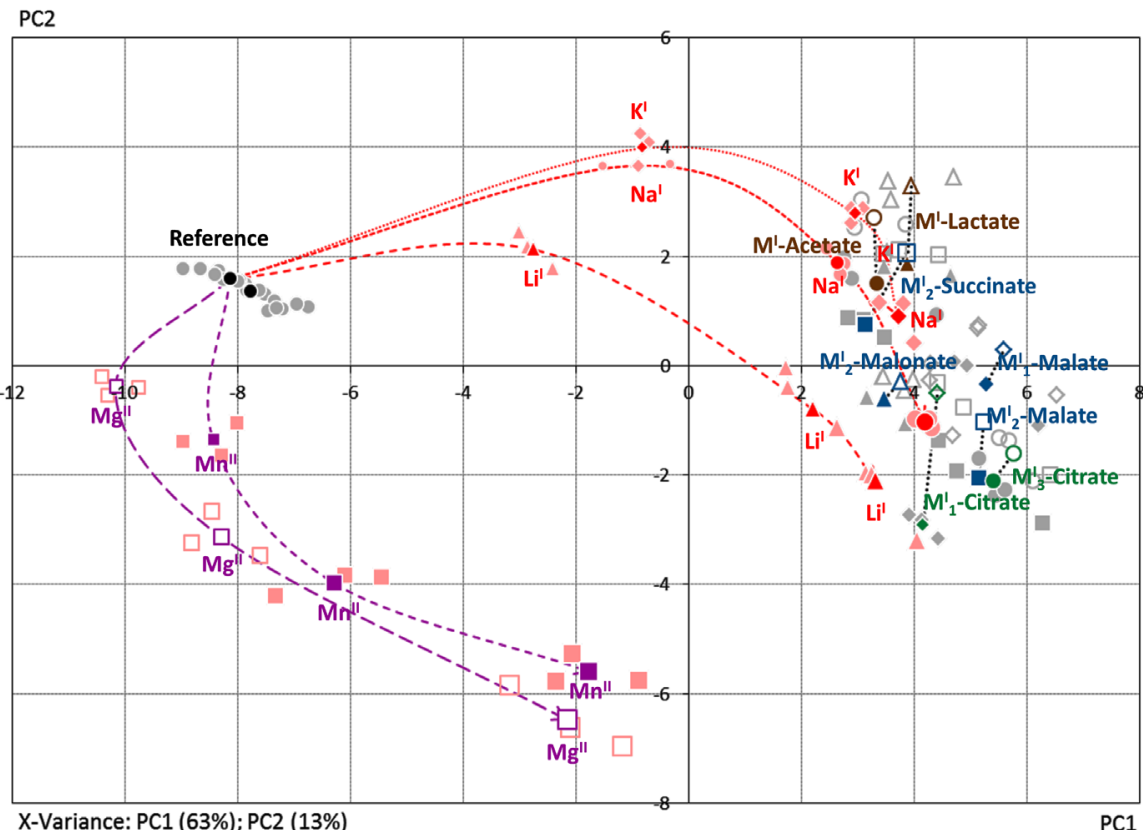

(a)

PC2

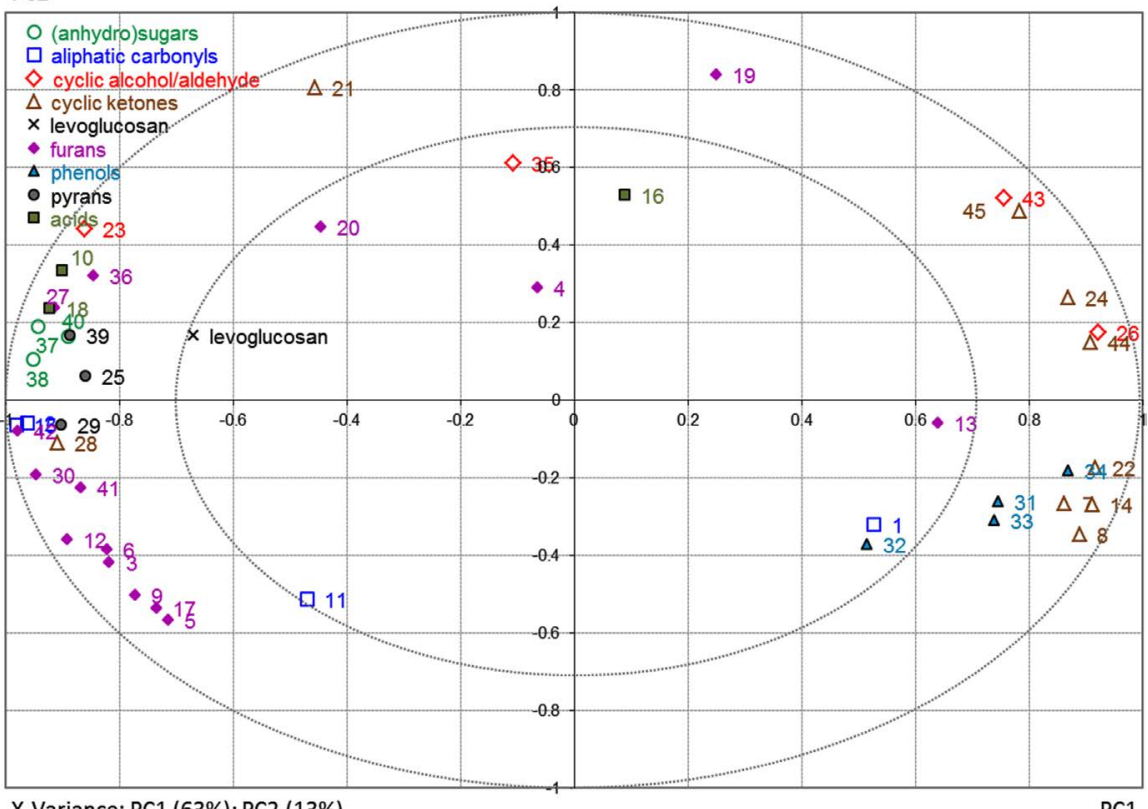

(b)

Figure 5. Scores (above) and Correlation Loadings (below) Plots of the combined pyrolysis data from both series of impregnated papers (anions and cations). Color assignment of Scores and Loadings Plots do not correspond!

suggest that the pyrolysis pattern is mainly determined by the type and concentration of cation rather than by the anion. The pyrolysis data have been analyzed by principal component analysis and the results allow a considerably precise interpretation of a large data matrix containing 111 objects (samples) and 46 variables (pyrolysis products). 
Interpretation of the data by means of the respective scores and loadings plots reveal that the formation of certain pyrolysis products can be guarded by adjusting the cationic additive type and concentration.

Further investigation of this topic will include a variation of the counter cations of various acids as well as a concentration series for anionic additives. In addition, other counter anions will have to be investigated in more detail in order to specifically attribute as many effects as possible.

\section{Acknowledgements}

The financial support of this work by the Austrian Science Foundation (Österreichische Forschungs förderungs gesellschaft-FFG) BRIDGE Project No. $810983 / 10997$ and by Dr. Franz Feuerstein GmbH, Traun, Austria, is gratefully acknowledged.

\section{References}

[1] Kashiwagi, T. and Nambu, H. (1992) Global Kinetic Constants for Thermal Oxidative Degradation of a Cellulosic Paper. Combustion and Flame, 88, 345-368.

https://doi.org/10.1016/0010-2180(92)90039-R

[2] Gupta, A.K. and Müller, P. (1999) Pyrolysis of Paper and Cardboard in Inert and Oxidative Environments. Journal of Propulsion and Power, 15, 187-194. https://doi.org/10.2514/2.5441

[3] Baldry, P.J., Cullis, C.F., Goring, D. and Hirschler, M.M. (1987) The Combustion of Cigarette Paper. Fire and Materials, 12, 25-33. https://doi.org/10.1002/fam.810120105

[4] Shafizadeh, F. (1968) Pyrolysis and Combustion of Cellulosic Materials. Advances in Carbohydrate Chemistry, 23, 419-474. https://doi.org/10.1016/S0096-5332(08)60173-3

[5] Arseneau, D.F. (1971) Competitive Reactions in the Thermal Decomposition of Cellulose. Canadian Journal of Chemistry, 49, 632-638. https://doi.org/10.1139/v71-101

[6] Shafizadeh, F. and Lai, Y.Z. (1972) Thermal Degradation of 1,6-Anhydro$\beta$-D-glucopyranose. Canadian Journal of Chemistry, 37, 278-284. https://doi.org/10.1021/jo00967a020

[7] Bradbury, A.G.W., Sakai, Y. and Shafizadeh, F. (1979) A Kinetic Model for Pyrolysis of Cellulose. Journal of Applied Polymer Science, 23, 3271-3280. https://doi.org/10.1002/app.1979.070231112

[8] Agrawal, R.K. (1988) Kinetics of Reactions Involved in Pyrolysis of Cellulose-I. The Three Reaction Model. The Canadian Journal of Chemical Engineering, 66, 403-412. https://doi.org/10.1002/cjce.5450660309

[9] Agrawal, R.K. (1988) Kinetics of Reactions Involved in Pyrolysis of Cellulose-II. The Modified Kilzer-Broido Model. The Canadian Journal of Chemical Engineering, 66, 413-418. https://doi.org/10.1002/cjce.5450660310

[10] Diebold, J.P. (1994) A Unified, Global Model for the Pyrolysis of Cellulose. Biomass and Bioenergy, 7, 75-85. https://doi.org/10.1016/0961-9534(94)00039-V

[11] Ball, R., McIntosh, A.C. and Brindley, J. (1999) The Role of Char-Forming Processes in the Thermal Decomposition of Cellulose. Physical Chemistry Chemical 
Physics, 1, 5035-5043. https://doi.org/10.1039/a905867b

[12] Pouwels, A.D., Eijkel, G.B. and Boon, J.J. (1989) Curie-Point Pyrolysis-Capillary Gas Chromatography-High-Resolution Mass Spectrometry of Microcristalline Cellulose. Journal of Analytical and Applied Pyrolysis, 14, 237-280. https://doi.org/10.1016/0165-2370(89)80003-8

[13] Essig, M., Richards, G.N. and Schenk, E. (1989) Mechanisms of Formation of the Major Volatile Products from the Pyrolysis of Cellulose. Cellulose and Wood Chemistry and Technology. John Wiley \& Sons, New York.

[14] Statheropoulos, M. and Kyriakou, S.A. (2000) Quantitative Thermogravimetric Mass Spectrometric Analysis for Monitoring the Effects of Fire Retardents on Cellulose Pyrolysis. Analytica Chimica Acta, 409, 203-214. https://doi.org/10.1016/S0003-2670(99)00859-4

[15] Dobele, G., Dizhbite, T., Rossinskaja, G., Telysheva, G., Meier, D., Radtke, S. and Faix, O. (2003) Pre-Treatment of Biomass with Phosphoric Acid Prior to Fast Pyrolysis: A Promising Method for Obtaining 1,6-Anhydrosaccharides in High Yields. Journal of Analytical and Applied Pyrolysis, 68-69, 197-211. https://doi.org/10.1016/S0165-2370(03)00063-9

[16] Lédé, J. (2012) Cellulose Pyrolysis Kinetics: An Historical Review on the Existence and Role of Intermediate Active Cellulose. Journal of Analytical and Applied Pyrolysis, 94, 17-32. https://doi.org/10.1016/j.jaap.2011.12.019

[17] Mettler, M.S., Paulsen, A.D., Vlachos, D.G. and Dauenhauer, P.J. (2012) The Chain Length Effect in Pyrolysis: Bridging the Gap Between Glucose and Cellulose. Green Chemistry, 14, 1284-1288. https://doi.org/10.1039/c2gc35184f

[18] Mettler, M.S., Mushrif, S.H., Paulsen, A.D., Javadekar, A.D., Vlachos, D.G. and Dauenhauer, P.J. (2012) Revealing Pyrolysis Chemistry for Biofuels Production: Conversion of Cellulose to Furans and Small Oxygenates. Energy \& Environmental Science, 5, 5414-5424. https://doi.org/10.1039/C1EE02743C

[19] Moldoveanu, S. (2010) Pyrolysis of Organic Molecules with Applications to Health and Environmental Issues. Techniques and Instrumentation in Analytical Chemistry (Series), Elsevier, Amsterdam.

[20] Low, M.J.D. and Morterra, C. (1985) IR Studies of Carbons-V Effects of $\mathrm{NaCl}$ on Cellulose Pyrolysis and Char Oxidation. Carbon, 23, 311-316. https://doi.org/10.1016/0008-6223(85)90116-2

[21] Zaror, C.A., Hutchings, I.S., Pyle, D.L., Stiles, H.N. and Kandiyoti, R. (1985) Secondary Char Formation in the Catalytic Pyrolysis of Biomass. Fuel, 64, 990-994. https://doi.org/10.1016/0016-2361(85)90156-5

[22] Richards, G.N. (1987) Glycolaldehyde from Pyrolysis of Cellulose. Journal of Analytical and Applied Pyrolysis, 10, 251-255.

[23] Tanczos, I., Pokol, G., Borsa, J., Toth, T. and Schmidt, H. (2003) The Effect of Tetramethylammonium Hydroxide in Comparison with the Effect of Sodium Hydroxide on the Slow Pyrolysis of Cellulose. Journal of Analytical and Applied Pyrolysis, 68-69, 173-185. https://doi.org/10.1016/S0165-2370(03)00071-8

[24] Dobele, G., Rossinskaja, G., Telysheva, G., Meier, D. and Faix, O. (1999) Cellulose Dehydration and Depolymerization Reactions during Pyrolysis in the Presence of Phosphoric Acid. Journal of Analytical and Applied Pyrolysis, 49, 307-317. https://doi.org/10.1016/S0165-2370(98)00126-0

[25] Klampfl, C.W., Breuer, G., Schwarzinger, C. and Köll, B. (2006) Investigations on the Effect of Metal Ions on the Products Obtained from the Pyrolysis of Cellulose. 
Acta Chimica Slovenica, 53, 437-443.

[26] Zemann, A., Rohregger, I. and Zitturi, R. (2008) Determination of Small Ions with Capillary Electrophoresis and Contactless Conductivity Detection. Methods in $\mathrm{Mo}$ lecular Biology, 384, 3-19.

[27] Dobele, G., Rossinskaja, G., Dizhbite, T., Telysheva, G., Meier, D. and Faix, O.J. (2005) Application of Catalysts for Obtaining 1,6-Anhydrosaccharides from Cellulose and Wood by Fast Pyrolysis. Journal of Analytical and Applied Pyrolysis, 74, 401-405. https://doi.org/10.1016/j.jaap.2004.11.031

[28] Pan, W.-P. and Richards, G.N. (1989) Influence of Metal Ions on Volatile Products of Pyrolysis of Wood. Journal of Analytical and Applied Pyrolysis, 16, 117-126. https://doi.org/10.1016/0165-2370(89)85011-9

[29] Piskorz, J., Radlein, D. and Scott, D.S. (1994) Thermal Conversion of Cellulose and Hemicellulose to Sugars. In: Bridgwater, A.V., Ed., Proceedings of International Symposium on Advances in Thermochemical Biomass Conversion, Blackie Academic, London, 1432-1440.

[30] Piskorz, J., Scott, D.S. and Radlein, D. (1998) Composition of Oils Obtained by Fast Pyrolysis of Different Woods. Pyrolysis Oils from Biomass: Producing Analysing and Upgrading. American Chemical Society, Washington DC, 167-178.

[31] Scott, D.S., Paterson, L., Piskorz, J. and Radlein, D. (2000) Pretreatment of Poplar Wood for Fast Pyrolysis: Rate of Cation Removal. Journal of Analytical and Applied Pyrolysis, 57, 169-176. https://doi.org/10.1016/S0165-2370(00)00108-X

[32] Richards, G.N. and Zeng, G. (1991) Influence of Metal Ions and of Salts on Products from Pyrolysis of Wood: Applications to Thermochemical Processing of Newsprint and Biomass. Journal of Analytical and Applied Pyrolysis, 21, 133-146.

https://doi.org/10.1016/0165-2370(91)80021-Y 